\title{
Blossoming Child, Mourning Parent: A Qualitative Study of Trans Children and Their Parents Navigating Transition
}

\author{
Annie Pullen Sansfaçon (1) ${ }^{1}$ - Denise Medico ${ }^{2}$ Morgane Gelly ${ }^{1}$ - Valeria Kirichenko ${ }^{1}$. Frank Suerich-Gulick ${ }^{1}$. \\ on behalf of the Stories of Gender Affirming Care project
}

Accepted: 11 November 2021 / Published online: 29 November 2021

(c) The Author(s) 2021

\begin{abstract}
An increasing number of jurisdictions now facilitate transitions for trans and non-binary youth (TNBY), allowing them to legally change their name and gender marker and providing medical gender-affirming care to support transition needs. The literature demonstrates the benefits of such measures in reducing adverse mental health outcomes. Strong parental support is also identified as key to TNBY thriving. But studies also show that parents may struggle to accept their child's identity during transition and beyond, rendering this life stage particularly challenging for both parents and TNBY. This qualitative project traces the experiences of TNBY and their parents as they evolve from the discovery of diverse gender identity to affirmation. Participants were recruited through three Canadian specialty clinics offering gender-affirming care and interviews were conducted separately with 36 dyads of trans youth and one of their parents, for a total of 72 interviews. Data reveal notable differences between the experiences of TNBY and that of their parents. Many TNBY began questioning their gender secretly, waiting to be sure of it before disclosing it to parents. While coming out was often a relief for TNBY, it was experienced differently for their parents, who often struggled to accept their child's identity even while outwardly showing support. However, we found that TNBY and their parents were able to bridge this gap by engaging in the transition process together. Because TNBY's experiences of realization and affirmation differ from those of their parents, we reiterate the importance of centering TNBY voices when attempting to understand their experience.
\end{abstract}

Key words trans youth $\cdot$ parents of trans youth $\cdot$ transition $\cdot$ gender realization $\cdot$ gender affirmation $\cdot$ coming out $\cdot$ transaffirming care $\cdot$ comparative analysis

\section{Highlights}

- We compare trans youth's evolving experience of gender realization, affirmation, and transition with that of their parents.

- Parents' experiences often do not reflect the realities of their trans child.

- There is a temporal gap between parents and their child in the acceptance journey.

- The synchronizing of parent and youth's narratives and experiences brings deeper family connection.

- The parental report only does not provide sufficiently complete information to understand their child's experience.

Supplementary Information The online version contains supplementary material available at https://doi.org/10.1007/s10826021-02178-w.

Annie Pullen Sansfaçon

a.pullen.sansfacon@umontreal.ca

1 School of Social Work, Université de Montréal, School of Social Work, Pavillon Lionel Groulx, P.O. BOX 6128, Downtown Station, Montréal, Québec H3C3J7, Canada

2 Department of Sexology, Université du Québec À Montréal, Local W-R110 455, Boul. René-Lévesque Est, Montréal, Québec H2L 4Y2, Canada

\section{Introduction}

Trans and non-binary youth (TNBY) represent nearly $2 \%$ of the 13- to 17-year-old population (John et al., 2019). TNBY are young people who feel some incongruence between their gender identity, that is, their core sense of being a certain gender, such as "female", "male", or some other gender (Hildago et al., 2013) and their sex assigned at birth. Some TNBY may develop such a sense of incongruence that it leads to important levels of distress, sometimes referred to as gender dysphoria. Transitions, may it be social 
(e.g., change of presentation, clothing, hair, or gender pronouns), medical (taking hormone blockers, hormone therapy, etc.) or legal (change of name, gender marker), are known to help alleviate some of the negative experiences that may be related to gender dysphoria (Cohen-Kettenis et al., 2011; Wiepjes et al., 2018; Pullen Sansfaçon et al., 2018; Pullen Sansfaçon et al., 2019).

Literature also shows that young TNBY may go through different steps toward transition and that processes and pathways to questioning and affirming their gender identity are varied. According to Cohen-Kettenis and Klink (2015), TNBY with gender dysphoria may present with early onset gender dysphoria (usually early in childhood, before puberty) or late onset gender dysphoria. However, recent research in Canada and Switzerland suggests more developmental pathways. While some TNBY affirm their gender in early childhood (the Affirmed child), others only come out during puberty, even though they have felt the gender incongruence much earlier (the Silent child); other TNBY will not have experienced any issues with regard to their felt gender until puberty hits (Neutral youth) allowing for a more nuanced portrait of typical gender identity development and dissonance in early life (Pullen Sansfaçon et al., 2020a; Medico et al., 2020).

TNBY are therefore a diverse population, by their experiences and pathways to affirmation. While TNBY are known to be a very resilient population as they navigate challenging contexts saturated by transphobia (Singh, 2013; Pullen Sansfaçon et al., 2018; Shelton et al., 2018; Pullen Sansfaçon et al., 2021), they continue to encounter many adversities. For example, they are at high risk of suicide approximately $47 \%$ of trans people have experienced suicidal ideation (Scanlon, 2010). They are also at high risk of homelessness. However, studies have suggested that the difficulties TNBY experience are not intrinsically linked to the way they feel about their gender or their trans identity but are instead direct and indirect consequences of the negative social contexts in which they live, notably with regard to discrimination, violence and non-recognition as TNBY (Watson et al., 2017; DeVries et al., 2016).

Not surprisingly, supportive environments such as affirming parents or support from a chosen family, inclusive schools and access to trans-affirming medical care all promote increased well-being (Pullen Sansfaçon et al., 2018). For example, TNBY who are allowed to live in their authentic gender with strong parental support appear to have equally good mental health compared to their cisgender peers (Durwood et al., 2017; Olson, et al., 2016). As such, parental support appears to compensate for some of the effects of discrimination experienced by trans youth (Taliaferro et al., 2018; Simons et al., 2013), decreasing psychological distress and supporting the development of the child's resilience
(Katz-Wise et al., 2018; Wilson et al., 2016). Various studies have suggested that strong parental support leads to greater life satisfaction among trans youth and positively impacts their self-esteem (Katz-Wise et al., 2018; Ryan, 2009; Wong \& Drake, 2017).

However, while parental support is key, parents may encounter many challenges in adapting to the new reality and the adaptation process is often long (Pullen Sansfaçon et al., 2020b). Parents can experience grief and a sense of loss (Pullen Sansfaçon et al., 2020b; Aramburu Alegria, 2018; Coolhart et al., 2018; Wahlig, 2015) denial, disbelief, or anger (Pullen Sansfaçon et al., 2020b; Aramburu Alegria, 2018; Wahlig, 2015). Parents are often concerned about the safety and acceptance of their child by others (Pullen Sansfaçon et al., 2015; Pullen Sansfaçon et al., 2020b; Aramburu Alegria, 2018; Lawlis et al., 2017; Wahlig, 2015) and they may feel powerless (Pullen Sansfaçon et al., 2015), socially judged or isolated (Pullen Sansfaçon et al., 2015; Wahlig, 2015). Certain parents recount experiencing feelings of guilt looking back because they were unable to properly acknowledge and support their child early on (Aramburu Alegria, 2018). Some parents may also question whether the gender identity declared by their child is real, and wonder if it could be sudden and the result of peer influence (Littman, 2018)

Several elements have been shown to help parents overcome these challenges and move toward acceptance: becoming educated about trans issues (Pullen Sansfaçon et al., 2020b; Wong \& Drake, 2017), knowing they can protect their child from the negative repercussions of discrimination and help promote their child's happiness (Coolhart et al., 2018), and being proactive in the child's transition by accompanying them or advocating for them (Birnkrant \& Przeworski, 2017; Aramburu Alegria, 2018). Having professional and peer support has also been shown to be very helpful in this acceptance journey (Pullen Sansfaçon et al., 2015; Pullen Sansfaçon et al., 2020b; Aramburu Alegria, 2018).

While the past decades have seen many articles published on the experience of TNBY or of their parents, to our knowledge, the Stories of Care project was the first one to draw from dyadic interviews with both parent and child to understand their perspectives and gain a broader understanding of their experiences on this journey of medical transition. We present the results of this project that interviewed 36 TNBY who were accessing genderaffirming care in Canada and one parent of each child, for a total of 72 in-depth interviews (73 people as both parents were interviewed in one case). We explore and contrast their experiences of and observations on growing up trans, from early questioning and coming out to medical transition. 


\section{Methodology}

The project was conducted between 2016 and 2019 and aimed at learning more about the experiences of TNBY and their parents/guardians who have been referred to specialty clinics for gender-affirming medical care. Specifically, the team aimed at better understanding the issues affecting youth and their families, how TNBY experience their gender identity and, for those who experience gender dysphoria, how they deal with this. We are also attentive to the numerous issues that youth and their families face, including previous care, family dynamics, social issues, strengths and resiliency and other factors that affect their overall health and well-being.

We drew from inductive and reflexive (Braun and Clarke, 2021) Thematic Analysis methodology (Braun et al., 2019; Braun \& Clarke, 2006, 2021) which allowed for the project's complexity and multidisciplinary perspectives (See Pullen Sansfaçon et al., 2019). The project began with research questions rather than relying on an hypothesis: what issues affect trans children/youth and their caregivers who seek care; what strategies are used to express and/or address dysphoria; how are social and family situations navigated; what factors influence psychosocial wellbeing and quality of life; and, how is medical intervention experienced? Our research was informed by the values of trans-affirming approach which recognizes gender selfidentifications as non-binary, a standpoint which guided our research process from question settings, data collection, and analysis (Braun and Clarke, 2021).

Participants were recruited through three Canadian specialty clinics offering gender-affirming care: Meraki Health Center (Montreal), Children Hospital of Eastern Ontario (CHEO) (Ottawa), and Gender Dysphoria Assessment and Action for Youth (GDAAY) (Winnipeg). These clinics are specialized in providing health care to trans and gender diverse children and youth, and they offer assessment and medical options to TNBY wishing to undergo medical transition, including prescribing puberty blockers and/or hormone therapy to alleviate gender dysphoria. To recruit participants to the project, clinics generated a list of current patients that included both prepubescent TBNY and pubescent TNBY (that is, who had started medication such as puberty blockers and/or hormone therapy). A letter of invitation describing the study was sent by the clinics to each parent and child on the list, asking them to contact a research assistant at the corresponding site if they were interested in taking part in the project. Participants were selected according to diversity sampling principles (age, stages of puberty, gender identity, and medical interventions received) until the target sample number was achieved ( $n=12$ youth +12 parents for each clinic).
Data were collected using semi-structured qualitative interviews and a sociodemographic questionnaire. One interview guide was developed to use with TNBY and another with the parents, with variations in both interview guides to accommodate different developmental and medical stages of the youth. Parents and children were interviewed separately except for two younger children who asked to have their parent present for their interview, but parent did not answer questions; the sociodemographic questionnaire was completed by the parent. Interviews with TNBY focused on gender identity processing, coming out, family and social relationships and support as well as experiences of receiving gender-affirming care. Interviews with parents focused on their life situation, their perception of their child's gender identity development and transition process, and their support systems. We explored the family's pathway to clinical care and their overall experiences with medical interventions and other services they'd received in both the youth and parent interviews. Interview questions were detailed and extensive, allowing for coherence between interviews and sites, regardless of interviewers. Table 1 presents all the main questions from the youth and parent interview guides. The guides included additional suggested questions that could be asked to seek more details or descriptive replies if needed.

Parent interviews lasted from 24 to $105 \mathrm{~min}$ (average $57 \mathrm{~min}$ ) and youth interviews lasted 24-104 min (average $61 \mathrm{~min})$. All interviews were audio-recorded and transcribed, and participants were given pseudonyms. Interviews were conducted by interviewers who were trained in the trans-affirming approach, including two who selfidentified as trans. All interviewers had psychosocial and/ or intervention training either acquired through formal university education, or through community intervention past experiences with trans and non-binary people including youth.

The project was approved by each of the ethics boards responsible for the clinical sites (Meraki Health Center, CHEO, and GDAAY), as well as by the ethics boards responsible for the principal investigator and all coresearchers who had access to raw data. At the beginning of each interview, written consent was obtained from the parent/guardian and, depending on their age, assent, or written consent was obtained from TNBY. Because the interviews could bring up sensitive subjects, we established a formal safety protocol adapted to each site. In addition to providing a list of resources to participants, interviewers were clearly informed on steps to follow in case of imminent danger to a child or in case of neglect or abuse. The interviews also took place in the clinics where youth were followed, where a health professional was on call, during all interviews, in case of a situation where the safety protocol 


\begin{tabular}{|c|c|c|c|c|c|c|c|c|c|c|c|c|c|c|}
\hline & 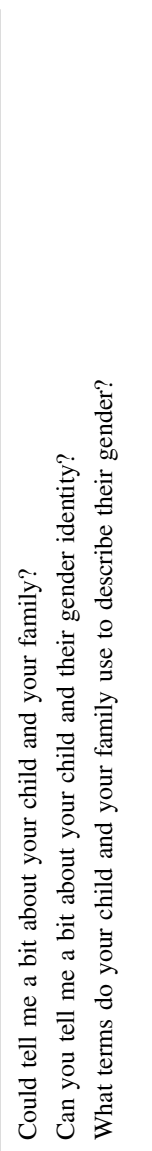 & 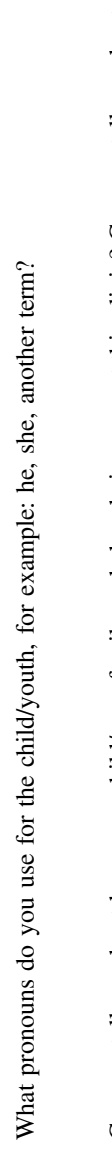 & 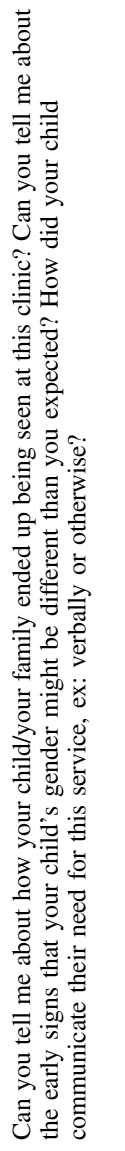 & 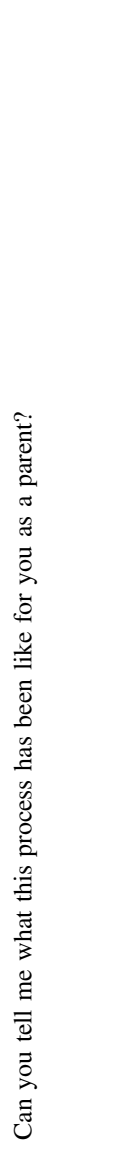 & 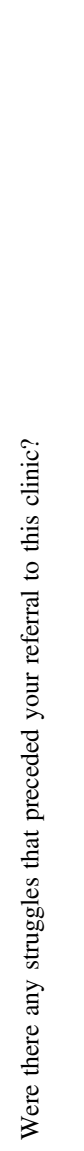 & 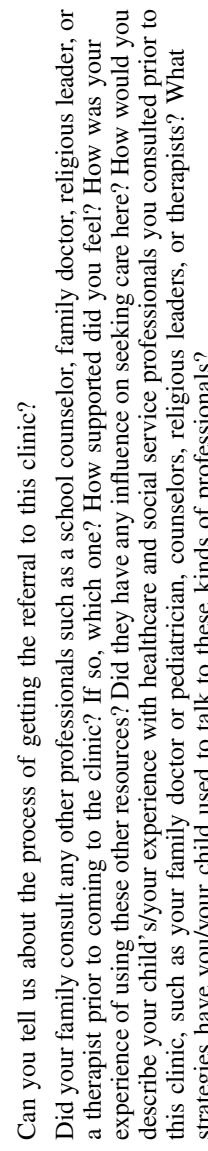 & 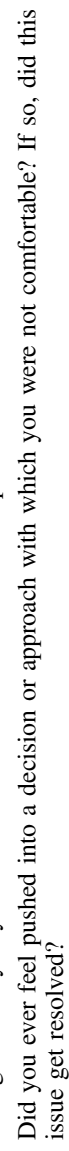 & 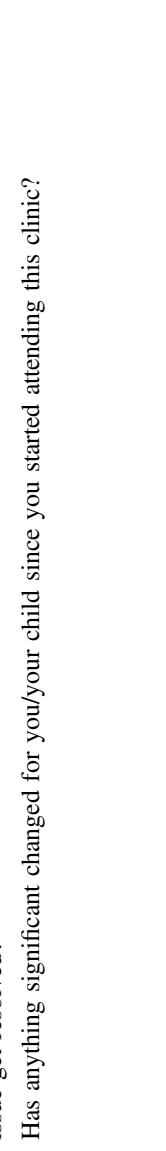 & 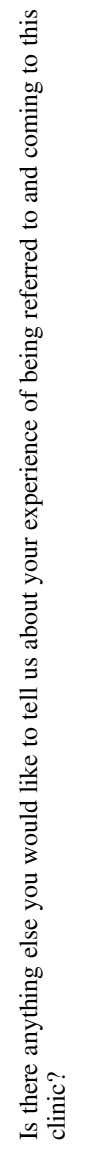 & 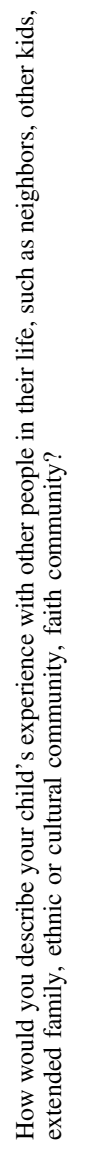 & 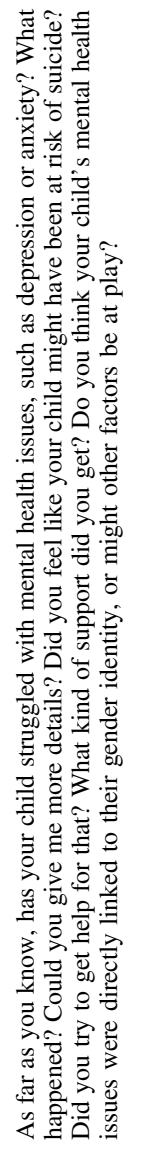 & 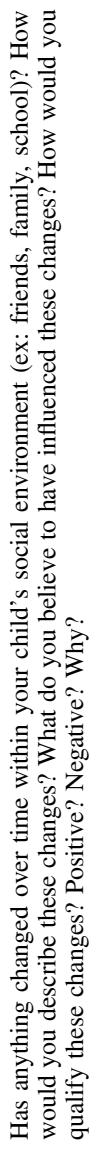 & 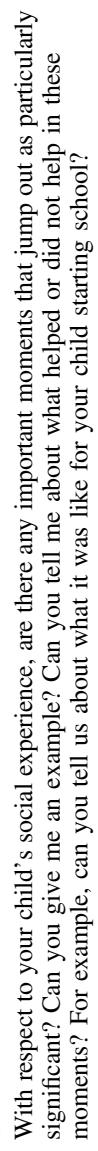 & 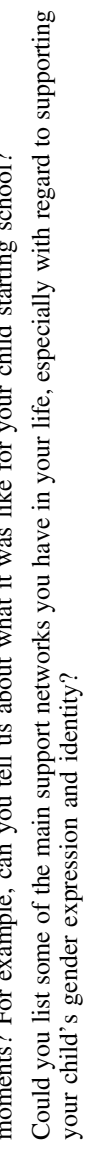 \\
\hline & 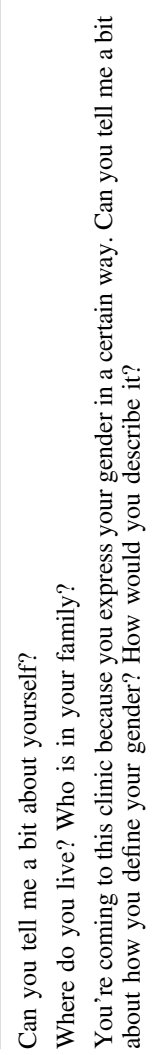 & 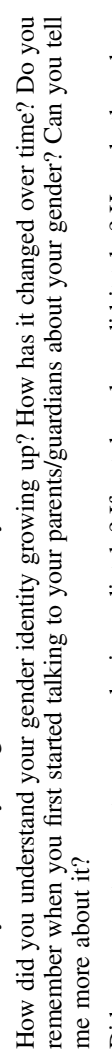 & 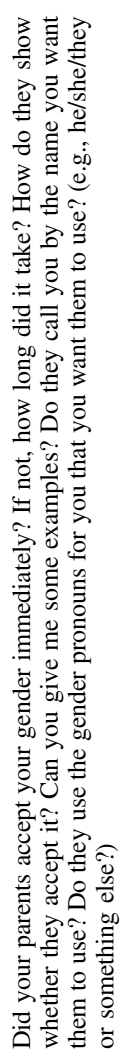 & 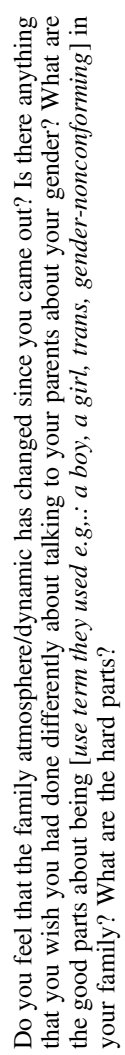 & 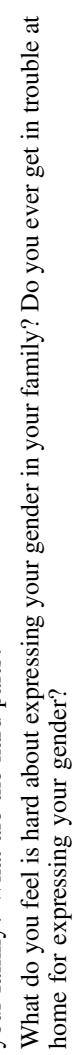 & 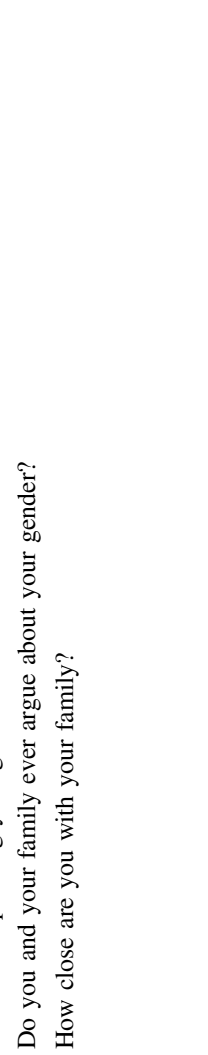 & 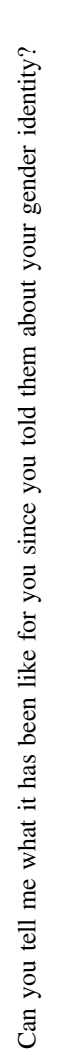 & 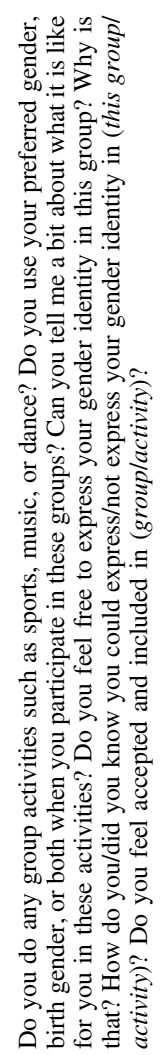 & 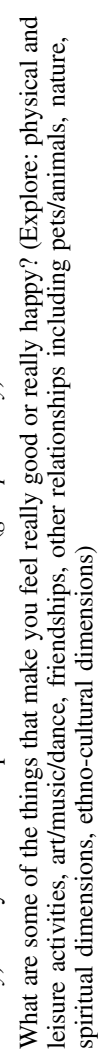 & 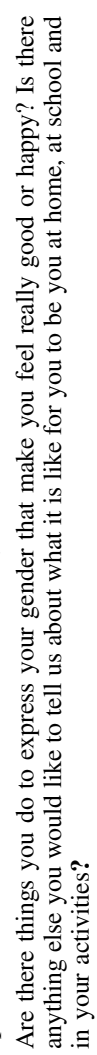 & 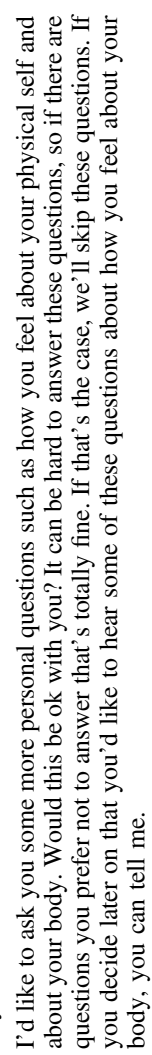 & 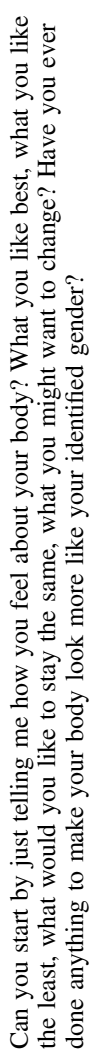 & 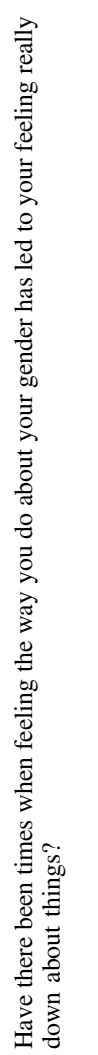 & 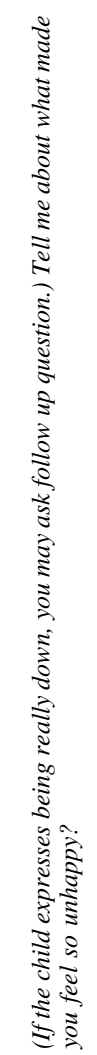 \\
\hline
\end{tabular}




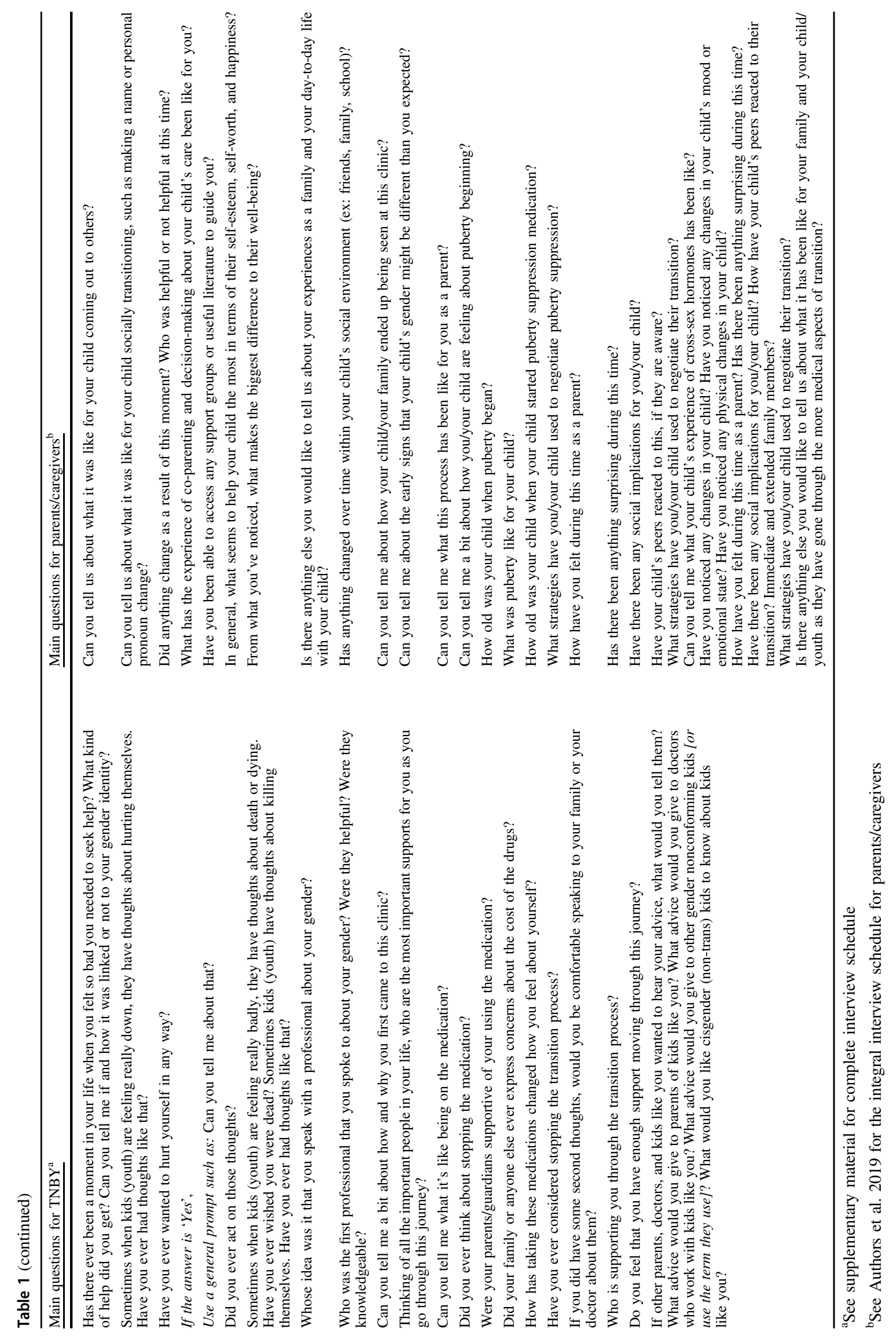


had to be initiated. No interview required, however, the use of the emergency protocol.

A total of 72 interviews were conducted in each clinic, 12 interviews were conducted with 12 TNBY attending the clinic (for a total of 36 interviews with youth), and 12 were conducted separately with one parent of the TNBY who self-selected (for a total of 36 interviews, including 4 fathers and 33 mothers). One of the parent interviews was conducted with both the mother and father, at their request). Among the parent interviewees, two described themselves as a foster parent or a guardian. We asked an open-ended question about the parents' ethnicities in the sociodemographic questionnaire. Most participants self-identified as white, Canadian, or Caucasian. Three of them selfidentified as coming from a mixed cultural heritage or European background, and eight of them preferred not to answer. Roughly a quarter of the participants had only one child (the child who was attending the clinic), half of them had two children, and another quarter had three to five. We did not ask the age of the parent participants. Among the youth participants there were five youth aged 9 to 12 years (14\%), 14 youth who were 13 to 15 years old (39\%) and 17 youth who were 16 to 17 years old (47\%). The average age was 14.5 , (median $=15.0$; standard deviation $=2.1$ years). A total of 21 youth were transmasculine (assigned female at birth), and 15 were transfeminine (assigned male at birth). Most of the youth described their identities in binary terms except three transmasculine youth who used non-binary terms to describe their identity, though they said they usually used male pronouns for themselves and their parents described their identity in binary terms. A fourth youth who described his identity in binary terms was described by his mother as "male and fluid."

Parents and youth interviews were first analyzed separately by two different research assistants (one for the youth interviews and one for the parents). A third research assistant was later brought into the project to proceed to a comparative analysis of youth and parent discourses. All research assistants are authors of this article. In coherence with our methodological choices, the themes were inductively generated from the interview material. First, initial codes were generated at a semantic level for both sets of interviews (TNBY and parents) (Braun \& Clarke, 2006), after which they were analyzed and categorized into themes. MAXQDA data analysis software was used to facilitate the process. Theme development continued as we began to write articles, an integral part of Thematic Analysis that helped us "define and refine" and write the "story" around these themes (Braun \& Clarke, 2006). Next, themes from the parents and youth interviews were set side by side and compared. Initially, seven themes emerging from TA process were compared: 1. "Youth's gender exploration and signs of gender nonconformity (GNC)" VS "signs of GNC observed by parents"; 2. Parent's reaction to GNC signs; 3 . Coming-out (announcement and first reactions); 4. Feelings about coming out; 5. Parental acceptance journey; 6. Feelings about the transition process; 7. Parental support. The naming of the theme has been evolving as the analysis progressed (Nowell et al., 2017). For each theme, we fist compared data by youth-parent dyads, looking for similarities and differences. We drew each parents' and youth's timelines to observe the gaps and synchronicities. We then examined and compared similarities and differences between dyads. From this analysis, we found five major points of convergence and divergence that we will present in the results: gender exploration, coming-out, blossoming child/mourning parents, parental support, and rewriting the narrative.

In order to ensure credibility, authenticity, and coherence of the data, we put in places some process throughout the data collection and analysis. The research assistant checked the verbatims with the audio-recording to ensure they capture emotions and experiences of participants as well as authenticity of the research material. The process of data analysis was overviewed by the principal investigator, so discussions between research assistants and principal investigators took place regularly for debrief meetings throughout the project, ensuring the credibility of the data (Nowell et al., 2017). During the meetings, authors examined the themes, as well as the coherence of the themes with the text content and ensured to agree on the interpretation. In case of disagreement, authors re-examined the section together and came to a decision through discussions until a consensus was reached. Data from the youth data set, and from the parents set was also published separately before comparing the perspectives, providing peer review assessment of initial interpretations of youth and their parent's perspectives. During the writing up stage of this article, each author who participated in the process was also able to check the final interpretation of data, ensuring coherence in the interpretation.

\section{Results}

When comparing trans youth interviews with their parents', we note that they experience different realities and temporalities. For example, TNBY all explored their gender much earlier than when they discussed this with their parents, or when their parents first realized about their gender. Our results also highlight that parents and TNBY experienced different milestones on similar timelines: thus, while youth felt a sense of relief when beginning to live as their authentic selves after having waited a long time to do so, parents were thrust into an often new reality that was usually filled with feelings of mourning and concern for 
their child. We also examined differences between what youth and their parents told us they felt internally and what they said they externally displayed to others. The gaps and divergences between youth's and parents' experiences were particularly salient during the gender exploration, the coming-out, and the transition process (blossoming children and mourning parents), but we notice that parental support was a milestone which brought youth and their parents closer, to finally share a common understanding and narrative of their journey.

\section{Gender Exploration}

Before the TNBY came out to them, many parents were unaware that their child might identify with a different gender from the one they'd been assigned at birth. Analysis of the parent and youth interviews suggests that parents and youth are out of phase when the child begins questioning their gender. This even appears in the narratives of children who transitioned in early childhood (the Affirmed child). While many parents noticed that their child acted outside gender norms or manifested some discomfort with their assigned gender, parents often interpreted this as a nonheterosexual sexual orientation or as simple gender nonconformity. For example, Juliette, a transfeminine participant, started to think she was a girl when she was 6 years old. Her parents saw that she was different and interpreted it as a sign that she might be gay.

"To be honest with you, Juliette has an older brother. I'd raised a boy and I could see the difference between them. And it was kind of, quote, 'a joke'. I used to say to my best friend all the time like, like I'm talking when Juliette was 3. [...] 'Like if Juliette doesn't turn out to be gay, you know, I would be very surprised."' (Juliette's parent)

In her interview, Juliette asserted that her dad thought she was gay and even tried to make her suppress her gender expression, which made her feel ashamed.

"I was 6 when I first was like, 'Maybe I'm a girl. Maybe I'm not'. [...] And then when I was 8, I started... Like my dad has always been like, 'You're gay, you're gay, you're gay." (Juliette, transfeminine)

There were also parents who said they didn't notice any obvious signs because according to them, there were none. For example, Brenda felt that her transmasculine child was not particularly masculine growing up.

"And it's not like [pause] he was always attracted to boy stuff when he was a baby or a toddler or anything like that, that's never been the case. His clothes have um, [pause] in the last year he has been wearing sweatpants and t-shirts. Didn't really think anything about it. [laugh] So yeah, I was pretty blindsided." (Josh's parent)

However, her child's interview highlights that he always expressed his gender androgynously: "I've never been a girly girl, I've always been... like I've always dressed pretty androgynous. So, I've never like... my mom bought me some super girly clothes and stuff, and I never wore them." (Josh, transmasculine)

In some cases, the youth said that they did not express their gender differently because they did not necessarily understand what was going on. In these cases, their coming out was often experienced by parents as a surprise.

"Tia never said 'I don't want a tuxedo, I want a dress." Tia never [gave any hints]. [There were] no hints, no hints, no hints at all, no hints whatsoever." (Tia's parent)

"I didn't know how to explain the way I felt, so, I'd just get really upset. I'd kind of channel my rage into video games, but then when I lost, well then I'd hit my desk, I'd hit the walls." (Tia, transfeminine)

These gaps between what youth experience and feel and what their parents are able to perceive-which can vary depending on their level of awareness and if youth manifest strong gender nonconformity or keep their reflection to themselves-seems to create a delay in parents' understanding of the situation which impacts their reaction to youth coming-out.

\section{Coming Out}

Some youth seemed to have delayed sharing their discomfort about their gender or coming out to their parents because they lacked the words to express it or because they wanted to protect their parents. For example, Jim recounted that he delayed coming out to his parents because of his parents' emotional/mental health issues. We also note that parents who became aware that their child might be trans or gender-diverse early on had less trouble adjusting to the new reality.

The child's coming out was also experienced very differently by parents and youth. Youth often described it as a relief after years of hiding their identity and worrying about disclosing it to their parents, while for the parents it was a new reality to process and adapt to. Before coming out, the youth said they'd experienced anxiety because they feared 
their parent's reaction. This apprehension led some youth to delay the disclosure, as Juliette recounts:

"I would try-I was trying to build up the guts to tell my mom. Like I wrote, I've written out so many notes and I crumpled them up and threw them in the garbage. I've thought like, 'Okay. Today's the day. Today's the day.' And then I go home. I go to school, I come home, I go to bed. I'm like, 'Forgot to tell her.' [...] I was just worried. Didn't know what the reaction was gonna be. So, I kinda just kept it." (Juliette, transfeminine)

Contrary to her fears, when Juliette finally came out to her mother, she reacted with immediate acceptance:

"And I said to her, "All that matters to me, at the end of the day, is that you're happy and you're healthy, that you're a well-rounded person. It makes no difference to me. You need to be who you are to be happy.' And I think she was a little surprised at that, but that's sort of the approach that we've taken, and that is truly how I feel." (Juliette's parent)

Though there was much variation in the stress or anxiety TNBY reported experiencing before coming out, many reported a common feeling of relief after coming out, especially when parents reacted better than expected, which was often the case in our sample. This may be a sample bias considering that all families we met were supportive enough to accompany their child to the specialty clinic to explore medical transition and to participate in the project. "It felt like this enormous pressure was removed all of a sudden. [...] To be accepted, and [no longer have to] hide." (Jeff, transmasculine). But regardless of the parent's reaction to the coming out, many parents started to feel stress, worry and even grief from this point onward, because they suddenly had to accept their child's emerging identity and manage a situation they were completely unfamiliar with. This was the case for Jeff's mother:

“Acceptance, it's, you know, it's a grieving process. I'm not losing my child, I still have my child, but it's not the same child. Well, not that it's not the same child, it's [sigh]. It's that, I can't explain it. It's something different." (Jeff's parent)

Coming out is thus a milestone where parent and child experience asynchrony of emotions as well as divergence in understanding. While the child has been thinking about their gender for a long time, their coming out is interpreted by their parent as sudden, since this reality has only just now been brought to their attention.

\section{Blossoming Child, Mourning Parents}

After the coming out, most parents said it took them time to adapt to their child's new reality. Here again, we note an important difference in the narratives: while youth described beginning to enjoy life at this point (in some cases, even ceasing self-destructive behavior), parents for their part were just embarking on a journey of adaptation and sometimes, of grieving. For parents, this included mourning the use of the name they'd originally given their child (frequently referred to as "the dead name" by trans people because they no longer use it). For example, Debbie's parent was still emotional when discussing the topic during the interview: "I named her [dead name]. And it absolutely broke my heart when she chose her own name. [cries] And it's not even a name I like [laughs]." In contrast, her daughter Debbie specifically listed "us[ing] [her] girl name, to forget [her] boy name from before" as one of the main things that made her feel good.

Not surprisingly, the overall transition process was often perceived and experienced differently by parents and their child. Youth were often excited to begin the medical transition and they wanted it to go faster, while some parents seemed to experience it as a shock, a process they wanted to embark on slowly:

"I realized that I accepted myself a lot more and it felt a lot less bad looking in a mirror after I took [puberty] blockers [a treatment prescribed to trans youth in order to pause puberty]." (Jeff, transmasculine)

"Yeah, it takes getting used to. The first time [dead name] got the blockers I cried for $2 \mathrm{~h}$ alone at night in my room, you know, it was. Accepting the loss of the daughter." (Jeff's parent)

Some parents also shared their concerns about the possibility of future regret, especially since from their perspective, the medical transition was progressing quickly, and it seemed for some to have started suddenly and "out of the blue". For many youth, however, the transition process was beginning after months or even years of reflection that their parents had been unaware of.

"And I have to make that decision. Right? And then live with the consequences of it. Right? And then I don't want to have a 25-year-old or 30-year-old saying, 'Why would you let me do that? I was 15years-old.' Right? I think that's my biggest fear, is that because I'm so, because I see so much female, so many female traits [...]. But Joey's impulsive. Like Joey, 'I want it, I want it, I want it.' And then 2 min 
later, 'I don't want it anymore.' Right? So, that's part of my concern.” (Joey's parent)

"I know my mom tells me all the time that she thought I was just gonna be a tomboy or something along the lines of that. But I always knew. There was never any different. It just got to a point where it was, I just wanted to stop talking about it. [...] That's it. But I never changed my mind or anything. That's never changed. [...] Those [rough] days I'm like, 'This needs to happen now. This has to happen."' (Joey, transmasculine)

However, we also note that in some families it was the parent who seemed to want transition to go faster and for changes to happen more quickly for their child, either because they thought it would make their child happier or because they were eager to turn over a new leaf and move on. In the same vein, some parents recounted struggling more when their child expressed their gender in a nonbinary manner, as was the case for Barbara's mother who seemed in a hurry "to have a daughter" instead of dealing with her child's ambiguous gender expression:

"At the same time sometimes, I wish it was faster, I'm like well there you still look like a guy, but do you want that or not [...] somehow, I can't wait for her to take estrogen, to have breasts and that it makes a difference. If we could do it all in a week, ok let's go. [...] Then it's done, damn it, it's over, here I have a daughter." (Barbara's mother)

In sum, the transition process is experienced by the youth as a long-waited liberation, a process by which they can finally express their authentic gender self-while, for parents, the beginning of the transition process generates shock and hesitation as they must grieve the erroneous image they had of their child. At the same time, discovering the authentic identity of their child facilitate the acceptance process.

\section{Parental Support}

After their child came out, most parents in our sample sought to help and support them. Driven by concern for their child's well-being, they became actively involved, confronting their own fears and unanswered questions by educating themselves or accompanying their child in their transition process. Most youth indicate feeling supported by their parents, even in cases where their parent said in their interview that they sometimes still struggled to accept their child's identity and deal with the situation. Some parents seemed to hide such feelings from their child in order to support them better, while some children tried to hide their own feelings from their parent so as not to worry them.

"[About confiding in his mother] Well, it depends on the topic. But I'd be surprised if she, because she cries easily, so it's always harder to talk to her, but otherwise, no, I can talk about anything. [...] Of course every time, I never know if she's crying because she's proud of where I've gotten to or because she's having trouble understanding." (Jim, transmasculine)

Becoming actively involved and showing support seemed in turn to help parents in their acceptance process. In fact, finally knowing they could do something to make their child happier was a relief for many parents who, prior to their coming out, had felt powerless to help their child as they struggled with difficulties such as mental health issues. In fact, this support was often mutual: when parents were supportive of their child's transition process, youth also found ways to help their parents navigate this journey by involving them and reassuring them. Parents tended to be more confident as a result, with more tools to support their child.

"Because a lot of the time, it's more Jim who explains it to me. Where things are at, how he's feeling with it, all that stuff, it's mainly him feeding me info. [...] 'Don't worry Mom, I'm doing really well."” (Jim's parent)

Some youth helped their parents through the process by preparing and informing them about issues faced by trans people. Other youth said they involved their parent in choosing their name: "I don't know what made me stick to 'Jason'. I just like I asked my mom, I think, one day, 'What would you have named me if I was a dude?' She's like, 'Jason' I was like, 'Okay.'” (Jason, transmasculine). Such symbolic gestures seemed important to some parents.

In many families, parent and child seemed to have grown closer as a result of their shared journey through the transition process, and as their child's well-being improved.

The child wasn't coming to me anymore. It was 'Good night' and that's it. We weren't interacting anymore and then, well, since we, since we started coming here [to the specialty clinic], now that we have some kind of structured supervision, it's easy. Now I get hugs, I get, we watch TV, the child started snuggling with me again. It's become easier. It's become easier [repetition in the recording]. The smile is back too. (Jim's parent)

So now I have my blockers and my mother, she's glad, she sees the changes from before I came out to 
today, I'm a lot happier. I'm making a lot more new friends, I go out more and I'm more just, happy to get up in the morning to go to school and I sleep better and all, so my mother's just glad to see that. (Jim, transmasculine)

Engaging in the transition process with their child, thus seemed to allow parents to strengthen their relationship with their child and for the two to grow closer.

\section{Rewriting the Narrative}

At the time of the interview, most of the parent and child narratives appeared to have become aligned in describing the present reality and in some cases, the past. For example, some parents who had been unaware of their child's transgender identity prior to their coming out said that looking back, they could see now what had probably been early signs of their child's identity or questioning that they hadn't noticed or understood as such at the time.

"I wouldn't say that we ever had any suspicions before he came and told us [...] but after he told us and I got to hear more about what he was feeling, a lot of things made sense afterward. [...] And I feel dumb about it now, that it never clicked to me that that was more than just him complaining. [...] And it seems obvious now." (Joseph's parent)

We also noticed that some parents and youth used the same transition-related anecdotes to tell their story in each of their interviews, suggesting they had discussed these experiences and synchronized their narratives as a result. For example, some youth shared anecdotes dating back to their early childhood, illustrating early gender questioning, that they did not remember themselves but that their parents had told them about. This was most frequent among youth who had expressed their gender early in life. Parents sometimes shared these same anecdotes in their own interview as the first indication for them that their child was "different". Similarly, some youth cited childhood photos taken by parents as evidence of early gender questioning. For example, Debbie, a young transfeminine participant, described a photo that her mother had taken of her in "girl pajamas [...] wearing barrettes." Drawing on these details their parents had shared with them seemed to allow youth to enrich their story and perhaps reinforce the sense that their current understanding of their gender resulted from a long journey of self-searching and exploration.

These examples show how parents' perspectives and those of their child met and complemented each other to confirm the youth's identity. Just as parents could lead youth to revisit their past with new insight, youth could lead parents to do the same. Some parents described the transition process as an eye-opening experience that changed their vision of parenthood and family dynamics, inducing a deeper emotional commitment between themselves and their child. Driven by the desire to support their child, they expanded their awareness of gender issues and committed themselves to learning about trans realities. Some parents stated that this experience made them better parents.

"And yeah, it opens my mind and my heart, and I realize it's so easy to hate and to be angry, and-but it's so much better to understand, to take the time to understand and to really be a kind person. [...] It makes us better parents I think. [...] Less judgmental, to let go." (Jason's parent)

In short, although parents and children began the transition process from very different places and perspectives. Our data showed how they could synchronize their narratives through time, dialog and mutual action, in some cases growing closer emotionally than they had ever been before.

\section{Discussion}

To our knowledge, this study was the first to have collected data dyadically but separately, from a large qualitative sample, and from parents and their TNBY. Our thematic analysis has allowed us to see that parents and children can experience many disconnects throughout the journey of gender exploration, coming out and adaptation/transition. Indeed, communication about gender can be complicated, which led some youth to hide their identity for years before they disclosed it to their parents. Parents also sometimes misinterpreted or were unable to see signs of their child's gender identity or questioning because they were unaware of trans issues or the existence of trans people. In these cases, disclosure often generated shock, grief and mourning for them-a phenomenon described at length by Coolhart et al., 2018 and Wahlig (2015).

Analyzing parent and child narratives concurrently allowed us to deepen our understanding of the processes and see that parent and child journeys leading to transition are often completely out of phase and sometimes appear to be going in opposite directions. Figure 1 illustrates the process.

First, the child begins to question their gender. This can be accompanied by feelings of discomfort, dysphoria, and anxiety. Many young people apprehend their parents' reaction and feel they have to hide their authentic identity, which can affect their self-esteem and mental health. Meanwhile, the majority of parents seem to ignore or deny the signs but often start to worry when their child starts 


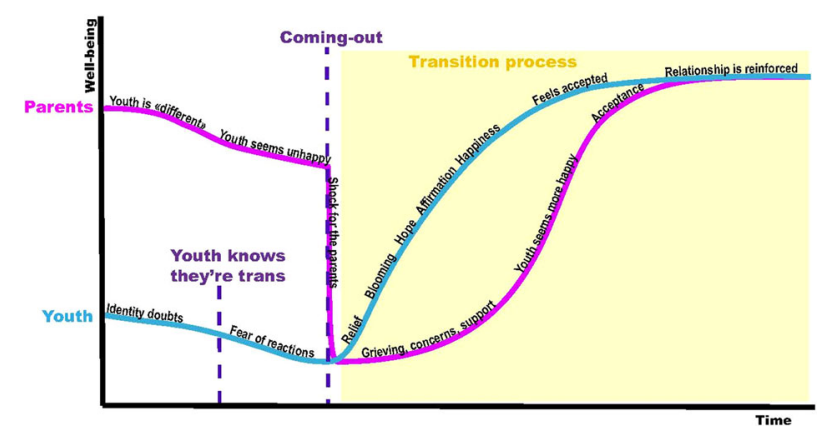

Fig. 1 Child and parent navigating gender realization, coming out and transition process

experiencing mental health struggles. Disclosure or coming out is a key moment, reversing the situation. Parents may experience shock and start to grieve their child and feel anxious about making the right decisions for their child, about safety and acceptance, etc.-in line with previous findings about parental reactions (Pullen Sansfaçon et al., 2020b; Aramburu Alegria, 2018; Coolhart et al., 2018; Wahlig, 2015)—while youth experience relief because they can finally be themselves, stop hiding their identity and start a transition process which reduces feelings of dysphoria. Youth well-being starts to improve as they feel hope and excitement in anticipation of these changes. By supporting their child, parents can alleviate their own concerns. Indeed, becoming actively involved in their child's transition process-by allowing them to explore their gender, by advocating for their child, or by focusing on their happinesswas often described by parent interviewees as a way to overcome challenges and to reconnect with their child. Coolhart et al., 2018 also explain how parents tend to prioritize their child's happiness as a coping mechanism to overcome their grieving process, which also clearly stands out in our data.

As their child affirms and embraces their gender identity, parents are able to finally see their child and recognize that they were never the child they thought they were. Often, this happens retrospectively as the parent and their child reinterpret the past together through a new lens. We also observe that allowing their child to explore their gender and seeing the positive changes that followed helped alleviate parents' concerns about future regrets and helped them buy into their child's decision, which confirms previous literature on the topic (Aramburu Alegria, 2018). The process that brings parents who decided to actively engage in supporting their youth despite their reluctance and fears also seem to lead to the creation of a virtuous circle, that is the process of positive change that itself contribute to developing further positive changes. Indeed, once the child felt initially able to disclose their gender identity to their parent, and once the initial shock is resolved, the growing support to youth itself helps the youth to feel happier and able to

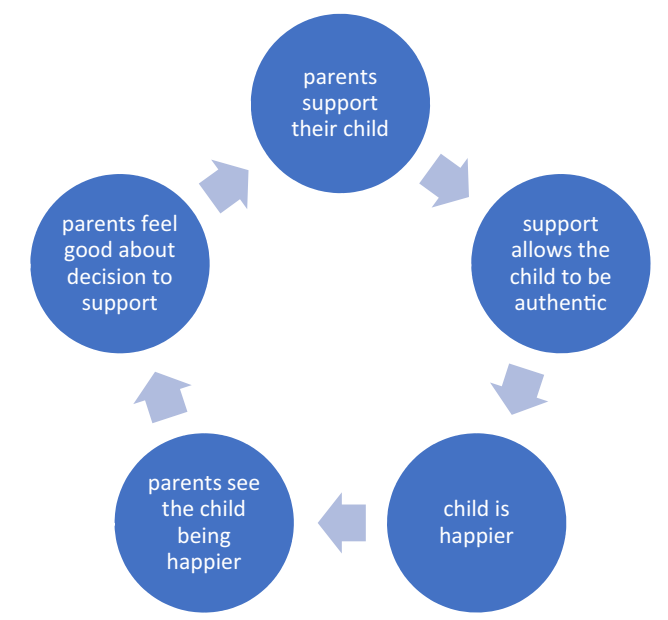

Fig. 2 Virtuous circle of support

live a more authentic gender self, which then feeds to parents feeling good about the decision to support youth, reinforcing the support that is provided to them. In families that are supportive, this whole process usually leads to better family dynamics, a closer emotional bond, and stronger mutual commitment. Figure 2 illustrates the process.

Our study also revealed a gap between parents and their child regarding gender expression that did not conform to social expectations for either binary gender. Notably, while some youth felt comfortable with an "in-between" gender expression and did not feel the urge to access certain medical interventions, their parents expressed the desire to see the changes occur faster, often in a binary way. This echoes Aramburu Alegria, 2018 who explains that parents reported anxiety when their child's gender expression was fluid or they manifested gender fluidity "between genders" (p. 142). While all the youth said they had benefited from the medical interventions they received, our data lead us to agree with this author's recommendation to further educate society on the diversity of gender identities. It is also important to note that while trans youth who engage in activities associated with their assigned gender are too often interpreted as wavering in their identity, this can actually reflect that the child is comfortable and secure enough in their authentic gender that they no longer feel as much pressure to prove their gender to others (Wong \& Drake, 2017).

By highlighting these differences in the transition journey, we wish to stress that parents and their child often have different needs that should be taken into consideration by professionals who accompany them in this process. Youth are often sure about their decisions and they need to access tools that allow them to express their gender (which often implies social and medical transition), while parents need to accept their child's identity and be reassured about their 
child's motivations and the consequences of their decisions. Some authors now tend to promote a trans-affirming approach to accompanying the child, meaning to let the child experience their gender without constraints or pressure (Keo-Meier \& Ehrensaft, 2018).

We note that a small number of parents in our sample noticed early on that their child was different, letting them explore their gender freely without trying to repress it. In these families, we observe less asynchrony and the transition process seems to be smoother since the child does not have to formally come out to their parents, as suggested by Travers (2018) and echoed in Aramburu Alegria, 2018 research on parents. This supports the importance of educating all parents on the existence and realities of trans identities so they can accompany their child's gender exploration as early as possible, if and when it occurs. As suggested in previous studies (Coolhart et al., 2018 Wong \& Drake, 2017; Pullen Sansfaçon et al., 2015; Pullen Sansfaçon et al., 2020b), we believe having more knowledge about trans issues would help parents feel better equipped to face such a situation and probably allow them to be more aware of any gender questioning, which in turn would help lessen their concerns. Indeed, parents in our study often cited having information and awareness of how parental support promotes well-being of TNBY (by reducing suicidality, for example) as having helped them in their acceptance journey.

\section{Implications for Practice, Policy, and Research}

Data obtained from both parents and youth shed light on how parents might have been unaware of extended gender questioning their child reported experiencing before coming out to their parents. This finding is important as it challenges the reliability of studies that rely exclusively on parental reports to understand youth's experiences and perspectives (for example, see Littman's (2018) study of parental reports suggesting a new developmental pathway for children). Through interviews with children and their parents, our data highlight that youth often begin their journey of gender questioning long before they first bring it to their parent's attention, often because youth fear their parents' reaction, or in some cases because they want to shield their parents from unnecessary concern. In some cases, parents misinterpreted or ignored signs that were more visible. This suggests that though parents may be surprised by their child's identity when they first reveal itespecially if parents did not notice any prior signs-this does not mean that a youth's gender identity has suddenly or "rapidly" appeared, as has been previously suggested (Littman, 2018). Our data show that most youth actually questioned their gender for years, waiting to be certain about their gender identity or for the timing to be right before disclosing it to their parents. Research aiming to understand gender identity development and affirmation in children should not rely solely on parental accounts because their perspectives are often widely different, as evidenced in this study. Hence, centering TNBY voices in this type of research is essential. Furthermore, our results highlight the importance of time in the process of adaptation and the different experiences that may emerge from it. While this project relied on memories of past experiences, future research should explore questions around gender realization and affirmation longitudinally to capture differences in the experience of parent and child more precisely. Finally, in terms of practice, our study reiterates the importance of offering support to both parents and TNBY separately, as they both have important yet different needs to fulfill in their journey to acceptance and affirmation.

\section{Limitations of the Study}

The results of this study need to be interpreted with caution. Because participants were recruited in clinics where they were already or just about to start gender-affirming care, results cannot be generalized to all youth and should only be applied to this particular group of young people. Also, parents had to agree to participate in an interview themselves for the child to be eligible to take part, which means that these parent participants can be considered to be fairly or even strongly supportive of their child. The experiences of parents and youth in families where parental support is limited may be different. For youth interviewed in presence of their parents, it may have an inhibited their answers. Finally, our sample size and limited sociodemographic diversity limit the generalizability of our results. For example, our parents' sample was mostly composed of mothers, so we have limited data on fathers' perspectives. There were also few parents who mentioned an experience of international migration or who revealed an ancestry other than white European descent. Further studies would benefit from greater diversity, though recruiting more diverse samples can pose significant challenges in this respect. Future studies could examine how parents' experience of their child's transition is influenced by the parent's gender.

\section{Conclusion}

Exploring both the experiences of youth and their parents in their process of coming out, adaptation to the new reality and acceptation allowed to uncover the asynchrony of experiences and emotions by which each of them more through. It also allowed us to discover, on the one hand, that the act of supporting their child allowed parents to regain some control over the situation: while many may, at the 
start, fell powerless to help their youth who was unhappy and in some cases self-harming or had suicidal thoughts or behaviors, discovering and understanding their child gender identity made them realize that they had the power to help their child get better. On the other hand, youth who felt accepted and supported and who could finally be themselves became happier and more open, which sometimes strengthened ties with parents. These positive changes made it easier for parents to accept their child's identity and gain confidence that transition was the right path and made sense within their child's history.

Funding This study was funded by the Canadian Institutes of Health Research, grant number PJT-148607.

\section{Compliance with Ethical Standards}

Conflict of Interest The authors declare no competing interests.

Ethical Approval All procedures performed in studies involving human participants were in accordance with the ethical standards of the institutional and/or national research committee and with the 1964 Helsinki Declaration and its later amendments or comparable ethical standards. The study was approved by the Comité d'éthique à la recherche en arts et en sciences of the University of Montreal, the institution of the principal investigator (approbation number CERAS2016-17-186-P); by the ethics boards responsible for the clinical sites: the Health and Research Ethics Board (HREB) of the University of Manitoba (approbation number HS20652(H2017:112)); by the CHEO Research Ethics Board, approbation number CHEOREB\# 16/176X; and by the McGill Faculty of Medicine Institutional Review Board, approbation number A06-B27-17B; as well as by the Comité d'éthique de la recherche avec des êtres humains de l'Université du Québec à Montréal, the institution of one of the co-applicants who has access to raw data (approbation number 2241_e_2017).

Publisher's note Springer Nature remains neutral with regard to jurisdictional claims in published maps and institutional affiliations.

Open Access This article is licensed under a Creative Commons Attribution 4.0 International License, which permits use, sharing, adaptation, distribution and reproduction in any medium or format, as long as you give appropriate credit to the original author(s) and the source, provide a link to the Creative Commons license, and indicate if changes were made. The images or other third party material in this article are included in the article's Creative Commons license, unless indicated otherwise in a credit line to the material. If material is not included in the article's Creative Commons license and your intended use is not permitted by statutory regulation or exceeds the permitted use, you will need to obtain permission directly from the copyright holder. To view a copy of this license, visit http://creativecommons. org/licenses/by/4.0/.

\section{References}

Aramburu Alegría, C. (2018). Supporting families of transgender children/youth: Parents speak on their experiences, identity, and views. International Journal of Transgenderism, 19(2), 132-143. https://doi.org/10.1080/15532739.2018.1450798.

Birnkrant, J. M., \& Przeworski, A. (2017). Communication, advocacy, and acceptance among support-seeking parents of transgender youth. Journal of Gay \& Lesbian Mental Health, 21(2), 132-153. https://doi.org/10.1080/19359705.2016.1277173.

Braun, V., \& Clarke, V. (2006). Using thematic analysis in psychology. Qualitative Research in Psychology, 3(2), 77-101. https:// doi.org/10.1191/1478088706qp063oa.

Braun, V., Clarke, V., Hayfield, N., \& Terry, G. (2019). Thematic analysis. In Dans P. Liamputtong (Éd.), Handbook of research methods in health social sciences (p. 843-860). Springer. https:// doi.org/10.1007/978-981-10-5251-4_103.

Braun, V., \& Clarke, V. (2021). Conceptual and design thinking for thematic analysis. Qualitative Psychology. https://doi.org/10. 1037/qup0000196.

Cohen-Kettenis, P. T., \& Klink, D. (2015). Adolescents with gender dysphoria. Best Practice \& Research Clinical Endocrinology \& Metabolism, 29(3), 485-495. https://doi.org/10.1016/j.beem.2015.01. 004.

Cohen-Kettenis, P. T., Schagen, S. E. E., Steensma, T. D., de Vries, A. L. C., \& Delemarre-van de Waal, H. A. (2011). Puberty suppression in a gender-dysphoric adolescent: A 22-year follow-up. Archives of Sexual Behavior, 40(4), 843-847. https://doi.org/10. 1007/s10508-011-9758-9.

Coolhart, D., Ritenour, K., \& Grodzinski, A. (2018). Experiences of ambiguous loss for parents of transgender male youth: A phenomenological exploration. Contemporary Family Therapy, 40 (1), 28-41. https://doi.org/10.1007/s10591-017-9426-x.

de Vries, A. L. C., Steensma, T. D., Cohen-Kettenis, P. T., VanderLaan, D. P., \& Zucker, K. J. (2016). Poor peer relations predict parent- and self-reported behavioral and emotional problems of adolescents with gender dysphoria: A cross-national, cross-clinic comparative analysis. European Child \& Adolescent Psychiatry, 25(6), 579-588. https://doi.org/10.1007/s00787-015-0764-7.

Durwood, L., McLaughlin, K. A., \& Olson, K. R. (2017). Mental health and self-worth in socially transitioned transgender youth. Journal of the American Academy of Child and Adolescent Psychiatry, 56(2), 116-123. https://doi.org/10.1016/j.jaac.2016.10.016. e2.

Ehrensaft, D., Giammattei, S. V., Storck, K., Tishelman, A. C., \& KeoMeier, C. (2018). Prepubertal social gender transitions: What we know; what we can learn-A view from a gender affirmative lens. International Journal of Transgenderism, 19(2), 251-268. https://doi.org/10.1080/15532739.2017.1414649.

Ehrensaft, D., \& Menvielle, E. (2011). Gender born, gender made: Raising healthy gender-nonconforming children (3rd revised ed. édition). The Experiment.

Hidalgo, M. A., Ehrensaft, D., Tishelman, A. C., Clark, L. F., Garofalo, R., Rosenthal, S. M., Spack, N. P., \& Olson, J. (2013). The gender affirmative model: What we know and what we aim to learn. Human Development, 56(5), 285-290. https://doi.org/10. $1159 / 000355235$.

Johns, M. M., Lowry, R., Andrzejewski, J., Barrios, L. C., Demissie, Z., McManus, T., Rasberry, C. N., Robin, L., \& Underwood, J. M. (2019). Transgender identity and experiences of violence victimization, substance use, suicide risk, and sexual risk behaviors among high school students-19 states and large urban school districts, 2017. Morbidity and Mortality Weekly Report, 68 (3), 67-71. https://doi.org/10.15585/mmwr.mm6803a3.

Katz-Wise, S. L., Ehrensaft, D., Vetters, R., Forcier, M., \& Austin, S. B. (2018). Family functioning and mental health of transgender and gender-nonconforming youth in the trans teen and family narratives project. The Journal of Sex Research, 55(4-5), 582-590. https://doi.org/10.1080/00224499.2017.1415291.

Keo-Meier, C., \& Ehrensaft, D. (2018). The gender affirmative model: An interdisciplinary approach to supporting transgender and gender expansive children. APA https://www.apa.org/pubs/ books/4317487.

Lawlis, S. M., Donkin, H. R., Bates, J. R., Britto, M. T., \& Conard, L. A. E. (2017). Health concerns of transgender and gender 
nonconforming youth and their parents upon presentation to a transgender clinic. Journal of Adolescent Health, 61(5), 642-648. https://doi.org/10.1016/j.jadohealth.2017.05.025.

Littman, L. (2018). Parent reports of adolescents and young adults perceived to show signs of a rapid onset of gender dysphoria. PLOS ONE, 13(8), e0202330. https://doi.org/10.1371/journal. pone. 0202330.

Medico, D. Pullen Sansfaçon, A., Zufferey, A., Galantino G., et Bosom M., (2020). Pathways to gender affirmation in trans youth: A qualitative and participative study with youth and their parents. Clinical Child Psychology and Psychiatry. 25(4), 1002-1014. https://doi.org/10.1177/1359104520938427.

Nowell, L. S., Norris, J. M., White, D. E., \& Moules, N. J. (2017). Thematic analysis: Striving to meet the trustworthiness criteria. International Journal of Qualitative Methods, 16(1), 1609406917733847. https://doi.org/10.1177/1609406917733847.

Olson, K. R., Durwood, L., DeMeules, M., \& McLaughlin, K. A. (2016). Mental health of transgender children who are supported in their identities. Pediatrics, 137(3), e20153223.

Pullen Sansfacon, A. Gelly, \& M et Ens Manning, K. (2021). Affirmation and safety: An intersectional analysis of trans and nonbinary youths in Quebec. Social Work Research, 45(3), 207-219. https://doi.org/10.1093/swr/svab009.

Pullen Sansfacon, A., Medico, D., Surich-Gullick, F., \& et Temple Newhook, J. (2020a). "I knew that I wasn't cis, I knew that, but I didn't know exactly": gender identity development, expression and affirmation in youth who access gender affirming medical care. International Journal of Transgender Health, 21(3), 307-320. https://doi.org/10.1080/26895269.2020.1756551.

Pullen Sansfaçon, A., Kirichenko, V., Holmes, C., Feder, S., Lawson, M. L., Ghosh, S., Ducharme, J., Temple Newhook, J., \& SuerichGulick, F. (2020b). Parents' journeys to acceptance and support of gender-diverse and trans children and youth. Journal of Family Issues, 41(8), 1214-1236. https://doi.org/10.1177/ $0192513 X 19888779$.

Pullen Sansfaçon, A., Suerich-Gulick, F., Temple-Newhook, J., Feder, S., Lawson, M., Ducharme, J., Ghosh, S., \& Holmes, C. (2019). The experiences of gender diverse and trans children and youth considering and initiating medical interventions in Canadian gender-affirming speciality clinics. International Journal of Transgenderism, 20(4), 371-387. https://doi.org/10.1080/ 15532739.2019.1652129.

Pullen Sansfaçon, A., Hébert, W., Ou Jin Lee, E., Faddoul, M. Tourki, \& D et Bellot, C. (2018). Digging beneath the surface: Results from stage one of a qualitative analysis of factors influencing the wellbeing of trans youth in Quebec. Journal of Transgenderism, 19(2), 184-202. https://doi.org/10.1080/15532739.2018.1446066.

Pullen Sansfaçon, A., Robichaud, M. J., \& Dumais-Michaud, A. A. (2015). The experience of parents who support their children's gender variance. Journal of LGBT Youth, 12(1), 39-63.

Ryan, C. (2009). Helping families support their lesbian, gay, bisexual, and transgender (LGBT) children. https://www.researchgate.net/
publication/238756322_Helping_Families_Support_Their_ Lesbian_Gay_Bisexual_and_Transgender_LGBT_Children.

Scanlon, K., Travers, R., Coleman, T., Bauer, G., \& Boyce, M. (2010). Ontario's trans communities \& suicide: Transphobia is bad for our health. TransPULSE E-Bulletin, 1(2). https://tra nspulseproject.ca/wp-content/uploads/2010/11/E2English.pdf.

Shelton, J., Wagaman, M. A., Small, L., \& Abramovich, A. (2018). I'm more driven now: Resilience and resistance among transgender and gender expansive youth and young adults experiencing homelessness. International Journal of Transgenderism, 19 (2), 144-157. https://doi.org/10.1080/15532739.2017.1374226.

Simons, L., Schrager, S. M., Clark, L. F., Belzer, M., \& Olson, J. (2013). Parental support and mental health among transgender adolescents. Journal of Adolescent Health, 53(6), 791-793. https://doi.org/10.1016/j.jadohealth.2013.07.019.

Singh, A. A. (2013). Transgender youth of color and resilience: Negotiating oppression and finding support. Sex Roles: A Journal of Research, 68(11-12), 690-702. https://doi.org/10.1007/ s11199-012-0149-z.

Taliaferro, L. A., McMorris, B. J., \& Eisenberg, M. E. (2018). Connections that moderate risk of non-suicidal self-injury among transgender and gender non-conforming youth. Psychiatry Research, 268, 65-67. https://doi.org/10.1016/j.psychres.2018. 06.068.

Travers, A. (2018). The trans generation: How trans kids (and their parents) are creating a gender revolution. University Press, New York.

Wahlig, J. L. (2015). Losing the child they thought they had: Therapeutic suggestions for an ambiguous loss perspective with parents of a transgender child. Journal of GLBT Family Studies, 11 (4), 305-326. https://doi.org/10.1080/1550428X.2014.945676.

Watson, R. J., Veale, J. F., \& Saewyc, E. M. (2017). Disordered eating behaviors among transgender youth: Probability profiles from risk and protective factors. The International Journal of Eating Disorders, 50(5), 515-522. https://doi.org/10.1002/eat.22627.

Wiepjes, C. M., Nota, N. M., de Blok, C. J. M., Klaver, M., de Vries, A. L. C., Wensing-Kruger, S. A., de Jongh, R. T., Bouman, M.B., Steensma, T. D., Cohen-Kettenis, P., Gooren, L. J. G., Kreukels, B. P. C., \& den Heijer, M. (2018). The Amsterdam cohort of gender dysphoria study (1972-2015): Trends in prevalence, treatment, and regrets. The Journal of Sexual Medicine, 15(4), 582-590. https://doi.org/10.1016/j.jsxm.2018.01.016.

Wilson, E. C., Chen, Y.-H., Arayasirikul, S., Raymond, H. F., \& McFarland, W. (2016). The impact of discrimination on the mental health of trans*female youth and the protective effect of parental support. AIDS and Behavior, 20(10), 2203-2211. https:// doi.org/10.1007/s10461-016-1409-7.

Wong, W., \& Drake, S. J. (2017). A qualitative study of transgender children with early social transition: Parent perspectives and clinical implications. PEOPLE: International Journal of Social Sciences, 3(2), 1970-1985. https://doi.org/10.20319/pijss.2017. 32.19701985 . 